\title{
REDE DE APOIO NA CONCILIAÇÃO FAMÍLIA E TRABALHO: UMA REVISÃO SISTEMÁTICA DE LITERATURA
}

THE SUPPORT NETWORK IN THE CONCILIATION OF FAMILY AND WORK: A SYSTEMATIC REVIEW OF LITERATURE

RED DE APOYO EN LA CONCILIACIÓN FAMILIAR Y LABORAL: UNA REVISIÓN SISTEMÁTICA DE LA LITERATURA

Edson Pereira*

Odilon Gomes de Souza**

Luciane Najar Smeha**

Cristiane Bottoli***

Josiane Lieberknecht Wathier Abaid ${ }^{* * * *}$

\begin{abstract}
RESUMO
A conciliação entre atividades profissionais e vivência familiar constitui um desafio para qualquer pessoa. Diante da formação de uma família e, principalmente, na chegada de filhos, ajustes de papéis são necessários. Assim, o objetivo deste estudo foi compreender como têm sido descritas, na literatura científica, a interação trabalho e família e a rede de apoio em casais economicamente ativos com a chegada dos filhos. Trata-se de uma revisão sistemática de literatura com artigos publicados entre os anos 2011 a 2016. Os resultados apontam para uma mulher "multitarefas", que divide melhor os afazeres com o homem do que há alguns anos, principalmente no cuidado com os filhos. A rede de apoio social é de fundamental importância à família em formação e está representada principalmente pelo cônjuge, pelos avós e por outros. Discutem-se estratégias de enfrentamento no conflito família/trabalho e trabalho/família e a relevância de estudos futuros com rigor metodológico.
\end{abstract}

Palavras-chave: Conflito trabalho-família. Apoio familiar. Conjugalidade. Parentalidade.

\footnotetext{
Texto recebido em 7 de março de 2017 e aprovado para publicação em 23 de maio de 2018.

" Psicólogo formado pelo Centro Universitário Franciscano (atual Universidade Franciscana - UFN) do Rio Grande do Sul. Endereço: RS-509, km 6, no 4561 - Bairro São José, Santa Maria-RS, Brasil. CEP: 97095-000. E-mail: pedsonp@hotmail.com ** Acadêmico do Curso de Psicologia da UFN. Endereço: Rua Cristalino Machado Soares, 260, casa 6 - Camobi, Santa MariaRS, Brasil. CEP: 97110-210.E-mail: somes28@yahoo.com.br

*** Doutora em Psicologia (PUC-RS), docente de Psicologia e do Mestrado em Saúde Materno-Infantil na UFN. Endereço: Rua Silva Jardim, 1175 - Bairro Rosário, Santa Maria-RS, Brasil. CEP: 97010-491. E-mail: lucianes@ufn.edu.br

${ }^{* * * * *}$ Mestra em Psicologia da Saúde (UFSM), docente de Psicologia na UFN. Endereço: Rua Silva Jardim, 1175 - Bairro Rosário, Santa Maria-RS, Brasil. CEP: 97010-491.E-mail: cbottoli@ufn.edu.br

**** Doutora em Psicologia (UFRGS), orientadora, docente do Curso de Psicologia e do Mestrado em Saúde Materno-Infantil na UFN. Endereço: Rua Silva Jardim, 1175 - Bairro Rosário, Santa Maria-RS, Brasil. CEP: 97010-491. E-mail: josianelieb@ ufn.edu.br
} 


\begin{abstract}
The conciliation between professional activities and family life is a challenge for everybody. In face of the formation of a family and, especially, with the arrival of children, role adjustments are necessary. Therefore, the goal of this study was to understand how the interaction of work and family has been described in the scientific literature, in the context of the support network in economically active couples with the arrival of their children. This is a systematic review of the literature, including articles published between 2011 and 2016. The results reveal that the woman continues as a "multitask" member, who shares her chores better with the man compared to a few years ago, especially in caring for her children. The support network is extremely important to the family in its constitution, which is represented mainly by the spouse, grandparents, and others. Coping strategies in the family/work and work/family conflict are discussed, along with the relevance of future studies with methodological rigor.
\end{abstract}

Keywords: Work/family conflict. Family support. Conjugality. Parenting.

\title{
RESUMEN
}

La conciliación entre actividad profesional y vida familiar es un reto para cualquier persona. Antes de la formación de una familia, y sobre todo con la llegada de los hijos, los roles necesitan ser reajustados. En este contexto, el objetivo de este estudio fue comprender cómo se ha descrito, en la literatura científica, la interacción entre trabajo, familia y red de apoyo en parejas económicamente activas con la llegada de los hijos. Se trata de una revisión sistemática de la literatura publicada entre los años 2011 y 2016. Los resultados señalan a una mujer "multitareas", que divide los quehaceres con el hombre mejor que solía hacer antes, especialmente el cuidado de los niños. La red de apoyo social es crucial para familia en construcción, y está representada principalmente por el cónyuge, los abuelos y otros. Se discuten las estrategias de superación del conflicto familia/trabajo y trabajo/familia y la importancia de futuros estudios con rigor metodológico.

Palabras clave: Conflicto trabajo-familia. Apoyo familiar. Conyugalidad. Parentalidad.

\section{INTRODUÇÃO}

$\mathrm{N}$

as últimas décadas, a sociedade vem sofrendo alterações. Entre estas, merece destaque a conciliação entre vida profissional e familiar, principalmente quando da chegada de um filho na vivência de um casal; além disso, com que apoio essa família em formação poderá contar dentro de uma rede de vínculos que constituiu. Sabe-se que o exercício do papel profissional é indispensável 
à manutenção econômica da família e à satisfação de vida. A constituição de uma família (para muitos) é o início de uma trajetória ao lado de outra pessoa que almeja os mesmos objetivos e que partilha os mesmos sonhos. A gestão dessas obrigações profissionais e familiares não está isenta de conflitos. Somado a isso, há de se considerar a pluralidade de formações familiares atualmente existentes, aliadas às relações socioeconômicas, políticas, tecnológicas, culturais que as perpassam e que afetam não somente a questão de escolhas alternativas de cuidados com os filhos, mas também a própria participação dos pais no cuidado com a criança (Vasconcelos, Seabra, Eisenberg, \& Moreira, 2012).

$\mathrm{Na}$ conciliação trabalho-família/família-trabalho, poderão surgir inúmeras e variadas situações que podem ser geradoras de conflitos referentes à discrepância nas responsabilidades do casal nos trabalhos domésticos e no cuidado com os filhos; a sobrecarga de trabalho e o cumprimento de metas exigido pela empresa; a presença de dependentes do casal, como deficientes, enfermos e pessoas idosas no lar, entre outras. Há toda uma dinâmica interna de funcionamento da família a ser assimilada e fatores externos a serem considerados. Mizrahi (2004) afirma que o transtorno que o trabalho impõe não pode estar dissociado do contexto familiar.

Integrar a criança ao sistema familiar, equilibrar dinâmicas familiares e vivência profissional tornam-se um desafio desse período transacional. A transformação da família está relacionada ao surgimento de novos papéis, além de reorganizar as tarefas do trabalho e do ambiente social. Ser pai, ser mãe é um processo exigente e suscita uma nova formatação familiar, seja pela definição de papéis parentais, seja pela redefinição das fronteiras em relação ao casal e ao externo. Dessen e Braz (2000) fazem a afirmação de que as mães se encontram mais envolvidas que os pais na tarefa de cuidar os filhos, porém, cada vez mais, o pai vem sendo fundamental na rede de apoio à mãe e à família.

Nessa perspectiva, o objetivo deste estudo foi compreender como, na literatura científica, têm sido descritas a interação trabalho e família com a chegada dos filhos e a rede de apoio social em casais economicamente ativos. Este artigo foi construído com ênfase no campo do conhecimento da Psicologia. Não se teve a pretensão de ampliar a discussão sobre o tema por meio de perspectivas teóricas mais específicas ou de outras áreas do conhecimento científico. Nos resultados e nas discussões das publicações, optou-se por não fazer comparativos com nenhuma teoria já construída sobre a temática, ou seja, fez-se a opção por ficar tão somente nos dados coletados de entrevistas e posterior análise dos autores, observando acordos e discrepâncias de concepções sobre o assunto. Num 
primeiro momento, apresentar-se-ão os conflitos inerentes na relação família $\mathrm{X}$ trabalho e trabalho $\mathrm{X}$ família. Se há conflitos, com que apoio poderá contar essa família em edificação. Essa será a apresentação seguinte: a rede de apoio a essa família.

\section{METODOLOGIA E PROCEDIMENTOS DE ANÁLISE}

O método adotado neste estudo foi a revisão sistemática, em que a pesquisa e a análise do material bibliográfico foram conduzidas em quatro etapas. $\mathrm{Na}$ primeira, foram selecionadas as bases de dados eletrônicos Periódicos Eletrônicos em Psicologia (Pepsic), The Scientific Electronic Library Online (Scielo) e Portal da Capes, entre os anos de 2011 e 2016, usando as seguintes palavras-chave, conforme Descritores em Ciências da Saúde (DECS): "família" e "trabalho"; "apoio social" e "relações familiares"; "parentalidade" e "creche"; "apoio social" e "parentalidade"; "apoio social" e "creche"; "parentalidade" e "relaçôes familiares"; "relações familiares" e "creche". Considerou-se a opção "todos os campos", não sendo realizado qualquer tipo de seleção por título ou por autor, por exemplo. A busca se limitou a artigos em língua portuguesa, dos quais se elencaram 2.110 artigos.

Na segunda etapa, foram estabelecidos os seguintes critérios de inclusão:

a) artigos empíricos escritos em língua portuguesa;

b) consideração à rede de apoio na vivência da parentalidade e em sua relação com o trabalho;

c) disponibilização ao texto completo.

Foram então descartados 2.014 artigos.

$\mathrm{Na}$ terceira etapa, os 96 artigos considerados potencialmente relevantes, dentro dos critérios, foram pré-selecionados com base no título e no resumo. Posteriormente, na quarta etapa, foi realizada uma análise minuciosa dos artigos pré-selecionados, de forma conjunta, em que foram descartados 76 artigos. Foi então que se definiram os artigos a serem revisados. Estes totalizaram um número final de 20 e foram dispostos em uma tabela, destacando suas características principais como: autores, título, ano de publicação, revista onde foi publicado e sua classificação mais recente na plataforma Sucupira (Qualis Capes), palavraschave, objetivos, participantes, desenho metodológico, resultados e base de dados eletrônicos. 


\section{RESULTADOS E DISCUSSŌES}

De 2.110 publicações encontradas nas buscas em cada base de dados, 20 artigos foram selecionados. O número final de artigos inclusos e também os motivos da exclusão dos demais são apresentados na figura 1 , a seguir.

Figura 1 - Diagrama de fluxo dos artigos revisados

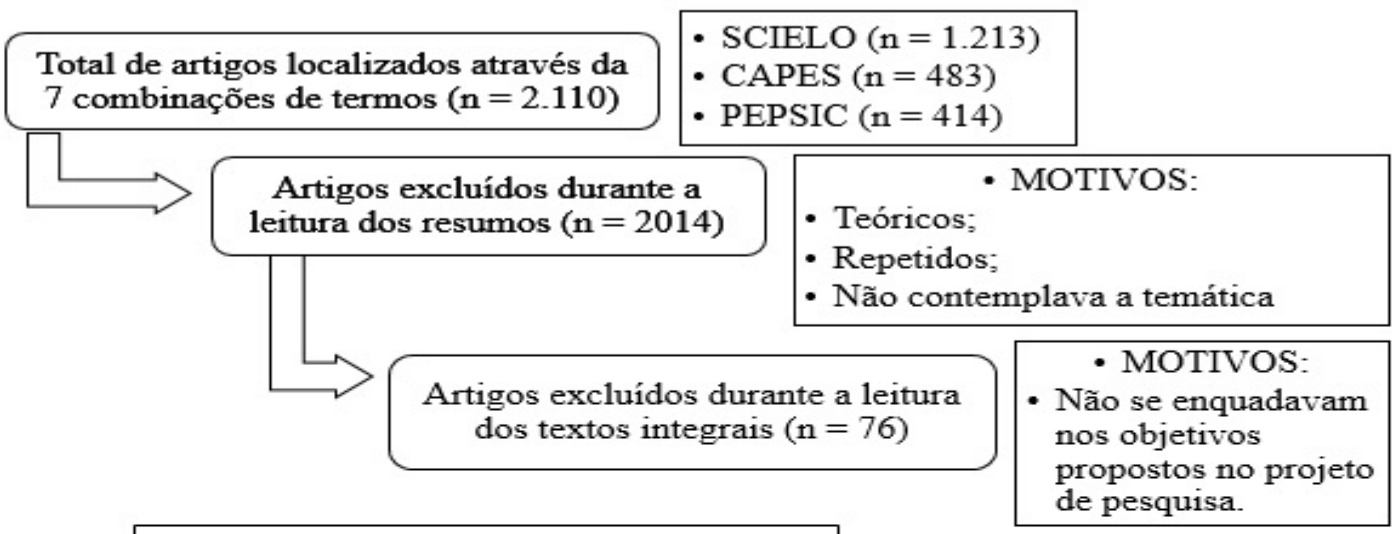

Total de artigos selecionados $(\mathrm{n}=20)$

- Casais $(\mathrm{n}=7)$

- Empresas $(\mathrm{n}=1)$

- Individual Avô $(\mathrm{n}=1)$

Mulheres $\left(\mathrm{n}_{1}=9\right)$

Homens $(\mathrm{n}=1)$

Trabalhadores $(\mathrm{n}=1)$

Figura 1: Diagrama de fluxo dos artigos revisados

Fonte: elaborado pelos autores.

Os dados coletados nos 20 artigos selecionados neste estudo estão tabulados nos quadros 1 e 2 , por ordem cronológica de publicação. 
Quadro 1 - Descrição dos artigos selecionados quanto ao título, autores, ano, revista, qualificação da Capes e palavras-chave

\begin{tabular}{|c|c|c|c|c|c|c|}
\hline № & Título & Autores & Ano & Revista & Qualis 2014 & Palavras-chave \\
\hline 1 & $\begin{array}{l}\text { Avaliação de necessidades para a } \\
\text { implementação de um programa } \\
\text { de transição para a parentalidade }\end{array}$ & $\begin{array}{l}\text { Murta, S. G., Rodrigues, A. } \\
\text { C., Rosa, I. O., Paulo, S. G., } \\
\text { Furtado, K. }\end{array}$ & 2011 & $\begin{array}{l}\text { Psicologia: } \\
\text { Teoria e } \\
\text { Pesquisa }\end{array}$ & $\begin{array}{l}\text { B-1 Psicologia; } \\
\text { B-2 Filosofia/ } \\
\text { teologia; } \\
\text { B-4 Ciências } \\
\text { Ambientais. }\end{array}$ & $\begin{array}{l}\text { Apego. Transição para a } \\
\text { parentalidade. Avaliação de } \\
\text { necessidades. Intervenção. } \\
\text { Prevenção. }\end{array}$ \\
\hline 2 & $\begin{array}{l}\text { Conciliação trabalho-família: } \\
\text { contribuições de medidas adotadas } \\
\text { por organizações portuguesas }\end{array}$ & Teixeira, R. \& Nascimento, I. & 2011 & $\begin{array}{l}\text { Revista Brasileira } \\
\text { de Orientação } \\
\text { Profissional }\end{array}$ & $\begin{array}{l}\text { A-2 Psicologia; } \\
\text { B-2 Ciências } \\
\text { Ambientais. }\end{array}$ & $\begin{array}{l}\text { Família. Trabalho. } \\
\text { Comprometimento } \\
\text { organizacional. }\end{array}$ \\
\hline 3 & $\begin{array}{l}\mathrm{D}(\mathrm{e}) \text { scolar de casa: dilemas } \\
\text { contemporâneos dos casais de } \\
\text { aeronautas }\end{array}$ & Jablonski, B., \& Silva M. S. & 2011 & $\begin{array}{l}\text { Psicologia em } \\
\text { Revista }\end{array}$ & $\begin{array}{l}\text { B-1 Psicologia; } \\
\text { B-2 Interdisciplinar; } \\
\text { B-3 Enfermagem. }\end{array}$ & $\begin{array}{l}\text { Divisão de tarefas } \\
\text { domésticas. Aeronautas. } \\
\text { Papéis de gênero. }\end{array}$ \\
\hline 4 & $\begin{array}{l}\text { Diferenças de género no conflito } \\
\text { trabalho-família: um estudo com } \\
\text { famílias portuguesas de duplo- } \\
\text { emprego com filhos em idade pré- } \\
\text { escolar }\end{array}$ & $\begin{array}{l}\text { Matias, M., Andrade, C., \& } \\
\text { Fontaine, A. M. }\end{array}$ & 2011 & Psicologia & $\begin{array}{l}\text { B-1 Psicologia; } \\
\text { B-1 Interdisciplinar } \\
\text { (Classificação de } \\
\text { Periódicos 2012). }\end{array}$ & $\begin{array}{l}\text { Conflito trabalho-família. } \\
\text { Conflito família-trabalho. } \\
\text { Famílias de duplo-emprego. } \\
\text { Género. }\end{array}$ \\
\hline 5 & $\begin{array}{l}\text { Influência recíproca entre atividade } \\
\text { profissional e vida familiar: } \\
\text { percepção de pais/mães }\end{array}$ & $\begin{array}{l}\text { Rocha, L. P., Almeida, M. C. } \\
\text { V., Silva, M. R. S., \& Cezar- } \\
\text { Vaz, M. R. }\end{array}$ & 2011 & $\begin{array}{l}\text { Acta Paulista de } \\
\text { Enfermagem }\end{array}$ & $\begin{array}{l}\text { B-1 Psicologia } \\
\text { (Classificação de } \\
\text { Periódicos 2012). }\end{array}$ & $\begin{array}{l}\text { Relações familiares. } \\
\text { Trabalho. Pré-escolar. }\end{array}$ \\
\hline 6 & $\begin{array}{l}\text { O lugar e a função do avô, aquele } \\
\text { que é pai duas vezes: um estudo a } \\
\text { partir de D. W. Winnicott }\end{array}$ & Naffah Neto, A. & 2011 & $\begin{array}{l}\text { Winnicott } \\
\text { e-prints }\end{array}$ & Não Qualis. & $\begin{array}{l}\text { Mercado de trabalho. } \\
\text { Feminismo. Pai. Mãe. Avô. } \\
\text { Avó. }\end{array}$ \\
\hline 7 & $\begin{array}{l}\text { Carreira e Família: divisão de } \\
\text { tarefas domiciliares na vida de } \\
\text { professoras universitárias }\end{array}$ & $\begin{array}{l}\text { Guimarães, M. G. V., \& } \\
\text { Petean, E. B. L. }\end{array}$ & 2012 & $\begin{array}{l}\text { Revista Brasileira } \\
\text { de Orientação } \\
\text { Profissional }\end{array}$ & $\begin{array}{l}\text { A-2 Psicologia; } \\
\text { B-2 Ciências } \\
\text { Ambientais. }\end{array}$ & $\begin{array}{l}\text { Família. Carreira. Tarefas } \\
\text { domésticas. Professoras } \\
\text { universitárias. }\end{array}$ \\
\hline
\end{tabular}




\begin{tabular}{|c|c|c|c|c|c|c|}
\hline 8 & $\begin{array}{l}\text { Trabalho familiar: distribuição } \\
\text { desejada do trabalho doméstico e } \\
\text { cuidados dos filhos entre cônjuges }\end{array}$ & $\begin{array}{l}\text { Silva, M. R. S., Luz, G. S., } \\
\text { Cezar-Vaz, M. R., \& Silva, } \\
\text { P. A. }\end{array}$ & 2012 & $\begin{array}{l}\text { Revista Gaúcha } \\
\text { de Enfermagem }\end{array}$ & $\begin{array}{l}\text { B-1 Enfermagem; } \\
\text { B-2 Saúde Coletiva. }\end{array}$ & $\begin{array}{l}\text { Relações familiares. } \\
\text { Cônjuges. Enfermagem } \\
\text { familiar. }\end{array}$ \\
\hline 9 & $\begin{array}{l}\text { Trajetórias profissionais de } \\
\text { mulheres executivas: qual o preço } \\
\text { do sucesso? }\end{array}$ & $\begin{array}{l}\text { Loureiro, C. M. P., Costa, I. } \\
\text { S. A., \& Freitas, J. A. S. B. }\end{array}$ & 2012 & $\begin{array}{l}\text { Revista de } \\
\text { Ciências da } \\
\text { Administração }\end{array}$ & $\begin{array}{l}\text { B-2 Interdisciplinar; } \\
\text { B-3 Sociologia; } \\
\text { B-4 Educação. }\end{array}$ & $\begin{array}{l}\text { Mulheres executivas. } \\
\text { Trajetórias. Carreiras. } \\
\text { Gênero profissionais. } \\
\text { Carreiras. Gênero. }\end{array}$ \\
\hline 10 & $\begin{array}{l}\text { "E agora, José?": } \\
\text { intraempreendedorismo, } \\
\text { desenvolvimento de competências } \\
\text { empreendedoras e conflito } \\
\text { trabalho-família em professores } \\
\text { de programas de mestrado e } \\
\text { doutorado em administração }\end{array}$ & $\begin{array}{l}\text { Takahashi, A. R. W., } \\
\text { Lourenço, M. L., Sander, J. } \\
\text { A., \& Souza, C. P. S. }\end{array}$ & 2012 & $\begin{array}{l}\text { Encontros } \\
\text { Científicos }\end{array}$ & $\begin{array}{l}\text { B-2 Interdisciplinar; } \\
\text { B-1 Administração, } \\
\text { Ciências Contábeis } \\
\text { e Turismo. }\end{array}$ & $\begin{array}{l}\text { Intraempreendedorismo. } \\
\text { Competências } \\
\text { empreendedoras. } \\
\text { Conflito trabalho-família. } \\
\text { Gênero. Programa de pós- } \\
\text { graduação. }\end{array}$ \\
\hline 11 & $\begin{array}{l}\text { A rede de apoio social e o papel da } \\
\text { mulher na geração de ocupação e } \\
\text { renda no meio rural }\end{array}$ & $\begin{array}{l}\text { Pinto, N. M. A., Pontes, F. A. } \\
\text { R. P., \& Silva, S. S. C. }\end{array}$ & 2013 & $\begin{array}{l}\text { Temas em } \\
\text { Psicologia }\end{array}$ & $\begin{array}{l}\text { A-2 Psicologia; } \\
\text { B-3 Enfermagem; } \\
\text { B-4 Sociologia. }\end{array}$ & $\begin{array}{l}\text { Família. Divisão sexual do } \\
\text { trabalho. Rede de } \\
\text { apoio social. } \\
\text { Meliponicultura. Ocupação. } \\
\text { Renda. }\end{array}$ \\
\hline 12 & $\begin{array}{l}\text { Antecedentes e consequências dos } \\
\text { conflitos entre trabalho e família }\end{array}$ & $\begin{array}{l}\text { Oliveira, L. B., Cavazotte, F. } \\
\text { S. C. N., \& Paciello, R. R. }\end{array}$ & 2013 & $\begin{array}{l}\text { Revista de } \\
\text { Administração } \\
\text { Contemporânea }\end{array}$ & $\begin{array}{l}\text { B-1 Psicologia; } \\
\text { B-1 Interdisciplinar; } \\
\text { B-2 Ciências Sociais. }\end{array}$ & $\begin{array}{l}\text { Conflito trabalho-família. } \\
\text { Qualidade de vida no } \\
\text { trabalho. Estresse. Intenção } \\
\text { de deixar a empresa. } \\
\text { Políticas de recursos } \\
\text { humanos. }\end{array}$ \\
\hline 13 & $\begin{array}{l}\text { Avós que assumem a criação de } \\
\text { netos }\end{array}$ & $\begin{array}{l}\text { Mainetti, A. C., \& } \\
\text { Wanderbroocke, A. C. N. S. }\end{array}$ & 2013 & $\begin{array}{l}\text { Pensando } \\
\text { Famílias }\end{array}$ & B-2 Psicologia. & $\begin{array}{l}\text { Família. Relacionamento } \\
\text { intergeracional. Avó. }\end{array}$ \\
\hline 14 & $\begin{array}{l}\text { A multiplicidade de papéis da } \\
\text { mulher contemporânea e a } \\
\text { maternidade tardia }\end{array}$ & $\begin{array}{l}\text { Lopes, M.N., Dellazzana- } \\
\text { Zanon, L. L., \& Boeckel, M. } \\
\text { G. }\end{array}$ & 2014 & $\begin{array}{l}\text { Temas em } \\
\text { Psicologia }\end{array}$ & $\begin{array}{l}\text { A-2 Psicologia; } \\
\text { B-3 Enfermagem; } \\
\text { B-4 Sociologia. }\end{array}$ & $\begin{array}{l}\text { Mulher. Maternidade tardia. } \\
\text { Família. }\end{array}$ \\
\hline
\end{tabular}




\begin{tabular}{|c|c|c|c|c|c|c|}
\hline 15 & $\begin{array}{l}\text { Da vida doméstica ao trabalho } \\
\text { formal: uma análise do processo } \\
\text { de inserção de donas de casa no } \\
\text { mercado de trabalho }\end{array}$ & $\begin{array}{l}\text { Rodrigues, H. S. J., \& } \\
\text { Izquierdo, J. }\end{array}$ & 2014 & Revista Ártemis & $\begin{array}{l}\text { B-4 Interdisciplinar; } \\
\text { B-3 Filosofia/ } \\
\text { teologia; } \\
\text { C- Educação. }\end{array}$ & $\begin{array}{l}\text { Processos de mudança } \\
\text { social. Mulheres. } \\
\text { Trabalho feminino. } \\
\text { Empoderamento. }\end{array}$ \\
\hline 16 & $\begin{array}{l}\text { Rede social de apoio de } \\
\text { enfermeiras-mães no cuidado com } \\
\text { os filhos }\end{array}$ & $\begin{array}{l}\text { Rodrigues, B. C., Mazza, V. } \\
\text { A., \& Higarashi, I. H. }\end{array}$ & 2014 & $\begin{array}{l}\text { Texto \& } \\
\text { Contexto } \\
\text { Enfermagem }\end{array}$ & $\begin{array}{l}\text { B-1 Psicologia; } \\
\text { A-2 Enfermagem; } \\
\text { B-2 Interdisciplinar. }\end{array}$ & $\begin{array}{l}\text { Mães. Enfermagem. } \\
\text { Trabalho. Apoio social. }\end{array}$ \\
\hline 17 & $\begin{array}{l}\text { Alocação de tempo em trabalho } \\
\text { pelas mulheres brasileiras }\end{array}$ & $\begin{array}{l}\text { Queiroz, V. S., \& Aragón, J. } \\
\text { A. O. }\end{array}$ & 2015 & $\begin{array}{l}\text { Estudos } \\
\text { Econômicos }\end{array}$ & $\begin{array}{l}\text { B-1 Administração, } \\
\text { Contabilidade, } \\
\text { Turismo; } \\
\text { B-1 Economia; } \\
\text { B-1 História. }\end{array}$ & $\begin{array}{l}\text { Oferta de trabalho feminina. } \\
\text { Horas de trabalho. } \\
\text { Família. Modelo heckit. } \\
\text { Modelo double hurdle. }\end{array}$ \\
\hline 18 & $\begin{array}{l}\text { Conciliação família-trabalho vivida } \\
\text { a dois: um estudo qualitativo com } \\
\text { casais com filhos pequenos }\end{array}$ & $\begin{array}{l}\text { Mendonça, M., \& Matos, } \\
\text { P. M. }\end{array}$ & 2015 & $\begin{array}{l}\text { Análise } \\
\text { Psicológica }\end{array}$ & B-4 Medicina I. & $\begin{array}{l}\text { Conciliação trabalho-família. } \\
\text { Intimidade. Casal. }\end{array}$ \\
\hline 20 & $\begin{array}{l}\text { Transição para a parentalidade e } \\
\text { a coparentalidade: casais que os } \\
\text { filhos ingressaram na escola ao } \\
\text { término da licença-maternidade }\end{array}$ & $\begin{array}{l}\text { Pasinato, L., \& Mosmann, } \\
\text { C. P. }\end{array}$ & 2016 & $\begin{array}{l}\text { Avances en } \\
\text { Psicología } \\
\text { Latinoamericana }\end{array}$ & $\begin{array}{l}\text { A-2 Psicologia; } \\
\text { B-1 Interdisciplinar; } \\
\text { B-2 Serviço Social. }\end{array}$ & $\begin{array}{l}\text { Dupla carreira. Escolas } \\
\text { maternais. Relações } \\
\text { familiares. }\end{array}$ \\
\hline
\end{tabular}

Fonte: elaborado pelos autores. 
Quadro 2 - Descrição do artigos selecionados quanto ao objetivo, participantes, instrumentos, resultados e base ou portal onde foi encontrado

\begin{tabular}{|c|c|c|c|c|c|}
\hline № & Objetivo & Participantes & Instrumentos & Resultados & Base/Portal \\
\hline 1 & $\begin{array}{l}\text { Descrever uma avaliação } \\
\text { de necessidades para um } \\
\text { programa de transição para a } \\
\text { parentalidade. }\end{array}$ & 13 casais & Entrevista & $\begin{array}{l}\text { Como estressores são revelados os cuidados } \\
\text { com o bebê, as mudanças nos papéis } \\
\text { familiares e a intrusividade da rede de apoio. }\end{array}$ & Scielo \\
\hline 2 & $\begin{array}{l}\text { Identificar e caracterizar } \\
\text { as medidas pró-familiares } \\
\text { adotadas por empresas. }\end{array}$ & 5 empresas & $\begin{array}{l}\text { Entrevista } \\
\text { semiestruturada }\end{array}$ & $\begin{array}{l}\text { Preocupação em proporcionar à sua força } \\
\text { de trabalho condições laborais que lhes } \\
\text { permitam gerir adequadamente as dimensões } \\
\text { profissional e familiar. }\end{array}$ & Scielo \\
\hline 3 & $\begin{array}{l}\text { Investigar a divisão de } \\
\text { tarefas domésticas e o } \\
\text { compartilhamento parental e } \\
\text { desigualdades de gênero. }\end{array}$ & 4 casais & $\begin{array}{l}\text { Entrevista } \\
\text { semiestruturada }\end{array}$ & $\begin{array}{l}\text { Mulheres despendem mais tempo com as } \\
\text { responsabilidades familiares, produzindo } \\
\text { um cenário desfavorável para a ascensão } \\
\text { profissional e para um maior envolvimento } \\
\text { dos homens na vida familiar. }\end{array}$ & Capes \\
\hline 4 & $\begin{array}{l}\text { Caracterizar os níveis de conflito } \\
\text { de papéis por famílias de duplo } \\
\text { emprego com filhos. }\end{array}$ & 246 casais & Questionário & $\begin{array}{l}\text { O CTF é distinto do CFT, e que esse processo } \\
\text { é particularmente distinto para homens e } \\
\text { mulheres. }\end{array}$ & Scielo \\
\hline 5 & $\begin{array}{l}\text { Mensurar a influência, tanto } \\
\text { da vida familiar na atividade } \\
\text { profissional como da atividade } \\
\text { profissional na vida familiar. }\end{array}$ & 92 casais & Questionário & $\begin{array}{l}\text { Cansaço físico e mental relacionado ao } \\
\text { trabalho influencia nas tarefas familiares. }\end{array}$ & Scielo \\
\hline 6 & $\begin{array}{l}\text { Realizar um estudo sobre a } \\
\text { função do avô no seio da família } \\
\text { contemporânea. }\end{array}$ & $\begin{array}{l}\text { Paciente em } \\
\text { análise }\end{array}$ & Relato de experiência & $\begin{array}{l}\text { Avô ocupa um lugar marginal, de maior } \\
\text { distanciamento com relação a papéis e } \\
\text { estereótipos familiares, o que Ihe permite } \\
\text { intervir em situações emergenciais, no } \\
\text { cuidado dos netos. }\end{array}$ & Scielo \\
\hline
\end{tabular}




\begin{tabular}{|c|c|c|c|c|c|}
\hline 7 & $\begin{array}{l}\text { Conhecer como se dá a divisão } \\
\text { das tarefas domésticas e } \\
\text { de cuidados com os filhos } \\
\text { pequenos em professoras } \\
\text { universitárias. }\end{array}$ & 86 professoras & Questionário & $\begin{array}{l}\text { As mulheres despendem mais horas no } \\
\text { trabalho doméstico e nos cuidados com } \\
\text { os filhos que seus companheiros e não se } \\
\text { sentem sobrecarregadas. }\end{array}$ & Pepsic \\
\hline 8 & $\begin{array}{l}\text { Investigar a distribuição de } \\
\text { trabalho familiar entre cônjuges } \\
\text { que têm vínculo empregatício e } \\
\text { filho(s) de até } 6 \text { anos. }\end{array}$ & 92 casais & Questionário & $\begin{array}{l}\text { O trabalho doméstico e cuidados dos filhos } \\
\text { ocorreram predominantemente como divisão } \\
\text { igual entre homem e mulher, sendo o cuidado } \\
\text { dos filhos uma responsabilidade maior da } \\
\text { mulher. }\end{array}$ & Capes \\
\hline 9 & $\begin{array}{l}\text { Entender como as executivas } \\
\text { percebem e traçam suas } \\
\text { carreiras. }\end{array}$ & 12 mulheres & Entrevista & $\begin{array}{l}\text { A carreira é importante como realização } \\
\text { pessoal, sem abrir mão da maternidade e/ou } \\
\text { do casamento. }\end{array}$ & Scielo \\
\hline 10 & $\begin{array}{l}\text { Analisar como docentes com } \\
\text { perfil intraempreendedor, lidam } \\
\text { com os conflitos oriundos da } \\
\text { relação trabalho-família. }\end{array}$ & 26 docentes & $\begin{array}{l}\text { Entrevista } \\
\text { semiestruturada }\end{array}$ & $\begin{array}{l}\text { Os resultados demonstraram que o } \\
\text { desenvolvimento de competências } \\
\text { empreendedoras traz conflitos nas relações } \\
\text { de trabalho-família. }\end{array}$ & Capes \\
\hline 11 & $\begin{array}{l}\text { Investigar a relação entre } \\
\text { rede de apoio social e papéis } \\
\text { desenvolvidos por mulheres. }\end{array}$ & 7 mulheres & $\begin{array}{l}\text { Entrevistas } \\
\text { semiestruturadas }\end{array}$ & $\begin{array}{l}\text { Intensa rede de apoio social mantida pelas } \\
\text { mulheres permitindo sua circulação em vários } \\
\text { contextos. }\end{array}$ & Pepsic \\
\hline 12 & $\begin{array}{l}\text { Avaliar impactos de políticas } \\
\text { formais e práticas informais } \\
\text { existentes nas empresas no CTF } \\
\text { e no CFT. }\end{array}$ & $\begin{array}{l}296 \\
\text { trabalhadores }\end{array}$ & Questionário & $\begin{array}{l}\text { Os resultados indicaram que o suporte } \\
\text { gerencial contribui para reduzir o CTF, } \\
\text { enquanto que a percepção de consequências } \\
\text { na carreira tende a promovê-lo. }\end{array}$ & Scielo \\
\hline 13 & $\begin{array}{l}\text { Estudar as mulheres que } \\
\text { passaram a assumir a criação } \\
\text { integral de um neto e as } \\
\text { representações dos papéis de } \\
\text { avó e mãe. }\end{array}$ & 10 mulheres & Entrevista & $\begin{array}{l}\text { Dados demonstram que ainda prevalece na } \\
\text { sociedade a ideia de que é a mulher que deve } \\
\text { assumir a criação dos filhos. }\end{array}$ & Capes \\
\hline
\end{tabular}




\begin{tabular}{|c|c|c|c|c|c|}
\hline 14 & $\begin{array}{l}\text { Investigar os múltiplos } \\
\text { papéis exercidos pela } \\
\text { mulher contemporânea e a } \\
\text { maternidade tardia. }\end{array}$ & 4 mulheres & $\begin{array}{l}\text { Ficha de dados } \\
\text { sociodemográficos } \\
\text { e entrevista } \\
\text { semiestruturada }\end{array}$ & $\begin{array}{l}\text { Há uma exigência de que a mulher progrida } \\
\text { profissionalmente e seja sua própria } \\
\text { mantenedora. O trabalho está relacionado } \\
\text { com a fonte de satisfação pessoal e financeira. }\end{array}$ & Pepsic \\
\hline 15 & $\begin{array}{l}\text { Analisar um grupo de mulheres } \\
\text { após a sua entrada no mercado } \\
\text { de trabalho. }\end{array}$ & $\begin{array}{l}\text { Mulheres donas } \\
\text { de casa }\end{array}$ & $\begin{array}{l}\text { Entrevistas } \\
\text { semiestruturadas }\end{array}$ & $\begin{array}{l}\text { Existe uma estreita relação entre o trabalho } \\
\text { remunerado e a independência feminina. }\end{array}$ & Scielo \\
\hline 16 & $\begin{array}{l}\text { Caracterizar o suporte social de } \\
\text { enfermeiras-mães no processo } \\
\text { de cuidar dos filhos. }\end{array}$ & $\begin{array}{l}10 \text { enfermeiras- } \\
\text { mães }\end{array}$ & $\begin{array}{l}\text { Entrevista } \\
\text { semiestruturada } \\
\text { e construção de } \\
\text { genogramas e } \\
\text { ecomapas das famílias }\end{array}$ & $\begin{array}{l}\text { Rede de apoio social da família essencial na } \\
\text { vida das mulheres, dando suporte, auxílio } \\
\text { e orientação no encaminhamento de suas } \\
\text { atividades. }\end{array}$ & Scielo \\
\hline 17 & $\begin{array}{l}\text { Investigar a alocação de horas } \\
\text { de trabalho pelas mulheres } \\
\text { brasileiras. }\end{array}$ & $\begin{array}{l}\text { Mulheres } \\
\text { trabalhadoras }\end{array}$ & $\begin{array}{l}\text { Dados da PNAD de } \\
2011\end{array}$ & $\begin{array}{l}\text { Os ciclos de vida, como casamento, } \\
\text { maternidade e construção da família reduzem } \\
\text { a oferta de trabalho das mulheres. }\end{array}$ & Scielo \\
\hline 18 & $\begin{array}{l}\text { Conhecer o modo como } \\
\text { casais com crianças pequenas } \\
\text { conciliam a vida profissional e } \\
\text { família. }\end{array}$ & 8 casais & $\begin{array}{l}\text { Entrevista } \\
\text { semiestruturada }\end{array}$ & $\begin{array}{l}\text { Existência de experiências de compensação, } \\
\text { segmentação e sobretudo de interferência na } \\
\text { conciliação entre o trabalho e a família. }\end{array}$ & Capes \\
\hline 19 & $\begin{array}{l}\text { Apresentar e ilustrar o potencial } \\
\text { do uso de histórias de vida, } \\
\text { influências e limites em } \\
\text { executivos brasileiros. }\end{array}$ & 7 executivos & Entrevistas & $\begin{array}{l}\text { Os resultados são apresentados em duas } \\
\text { grandes categorias de análise: influências do } \\
\text { contexto nas carreiras e momentos da vida e } \\
\text { escolhas profissionais. }\end{array}$ & Scielo \\
\hline 20 & $\begin{array}{l}\text { Investigar a transição } \\
\text { para a parentalidade e a } \\
\text { coparentalidade em casais } \\
\text { após o término da licença- } \\
\text { maternidade. }\end{array}$ & 4 casais & $\begin{array}{l}\text { Questionário de dados } \\
\text { sociodemográfcos } \\
\text { e entrevista } \\
\text { semiestruturada }\end{array}$ & $\begin{array}{l}\text { Durante a transição para a parentalidade, } \\
\text { os genitores preservam mais seus espaços } \\
\text { pessoais, enquanto as genitoras se sentem } \\
\text { sobrecarregadas. }\end{array}$ & Capes \\
\hline
\end{tabular}

Fonte: elaborado pelos autores 
Dos artigos estudados, 17 eram do Brasil e 3 de Portugal. Quanto aos anos e à quantidade de publicaçôes em cada um, os dados foram: 6 em 2011; 4 em 2012; 3 em 2013; 3 em 2014; 3 em 2015; e 1 em 2016. Parece haver um maior interesse pela temática após a aprovação da Lei Federal no 11.770, de 9 de setembro de 2008, que entrou em vigor em janeiro de 2010, regulamentada pelo Decreto ${ }^{\circ}$ 7.052 de 23 de dezembro de 2009, a qual prevê incentivo fiscal para as empresas do setor privado que aderirem à prorrogação da licença-maternidade de 120 dias para 180 dias. Nesse período de prorrogação da licença, a mãe não poderá exercer qualquer atividade remunerada, e a criança não poderá ser mantida em creche ou organização similar. Destaca-se que a maioria dos artigos encontrados são oriundos de estudos da área da Psicologia. Ainda que não tenha sido um critério de inclusão, esse perfil de artigos evidencia que há um importante interesse da área em compreender a interação trabalho e família e a rede de apoio em casais economicamente ativos com a chegada dos filhos.

Após a análise de conteúdo, emergiram duas categorias: conflito famíliatrabalho (CFT)/conflito trabalho-família (CTF) e rede de apoio. E, destas, emergiram subcategorias, conforme demonstrado na figura 2 .

Figura 2 - Categorias e subcategorias da análise de conteúdo realizada no estudo

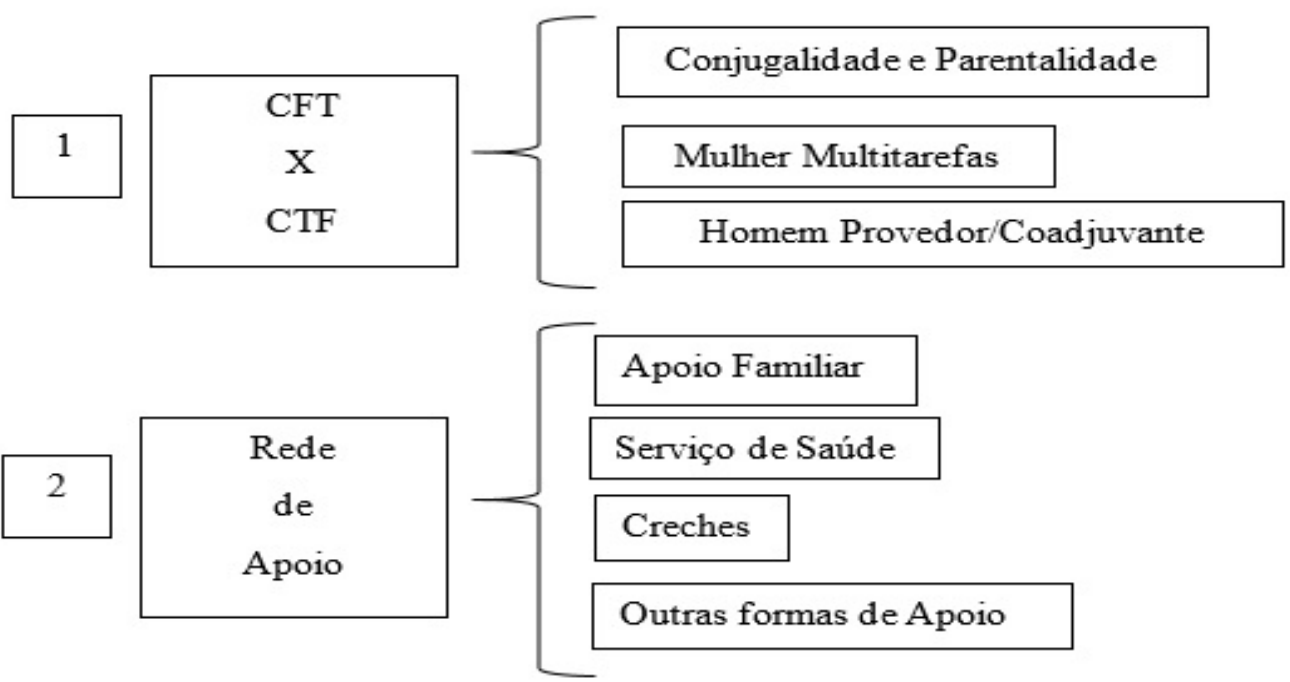

Figura 2: Categorias e subcategorias da Análise de Conteúdo realizada no estudo

Fonte: elaborado pelos autores. 


\subsection{CONFLITO FAMÍLIA-TRABALHO (CFT) X CONFLITO TRABALHO-FAMÍLIA (CTF)}

Esta categoria englobou itens dos artigos que mencionavam os conflitos da família que interferem no trabalho e do trabalho que interferem na família. Hoje, sabe-se que grande parcela da população que se encontra inserida no mercado de trabalho também constitui família. Por vezes, a incompatibilidade entre o trabalho e a família pode gerar conflito nas pessoas, vindo a refletir nesses dois contextos. Por um lado, percebem-se as crescentes pressões das empresas com o objetivo de aumentar os ganhos, exigindo dos empregados maior dedicação de seu tempo no trabalho. Por outro lado, com o aumento de famílias em que ambos os cônjuges se inserem no mercado de trabalho, há necessidade de uma melhor distribuição das tarefas domésticas e, com a chegada de filhos, o cuidado com estes. Assim, pode-se dizer que, quando as obrigaçôes referentes à família prejudicam o desempenho no trabalho, estabelece-se CFT. Ao contrário, quando as responsabilidades profissionais interferem no cumprimento das obrigações familiares, estabelece-se o CTF. Consideram-se duas percepçôes diferentes, mas que estão diretamente ligadas entre si. Há uma relação mútua de causa e de efeito entre CTF e CFT (Oliveira, Cavazotte, \& Paciello, 2013).

Nos estudos sobre a categoria CFT X CTF, emergiram três subcategorias. A primeira delas refere-se à conjugalidade/parentalidade. A conjugalidade faz uma relação de papéis de homem e de mulher ante a vivência do casal. Já a parentalidade refere-se à constituição do ser pai e do ser mãe, assumindo novos papéis no lar. A segunda subcategoria aponta para uma mulher multitarefas, uma mulher multifacetada que assume muitas funções tanto profissionais quanto domésticas e no cuidado com filhos. Por fim, a terceira subcategoria apontada nos estudos é a passagem do homem provedor para o homem coadjuvante no cuidado com os filhos e com as tarefas domésticas.

\subsubsection{CONJUGALIDADE/PARENTALIDADE}

No estudo feito por Closs e Oliveira (2015), 100\% dos executivos entrevistados relataram suas angústias ante o papel de ser pai ou de ser mãe, mantendo o ritmo de seus trabalhos. Pasinato e Mosmann (2016) observaram que os genitores devem adaptar-se à parentalidade como também saber negociar seus papéis e suas funções juntamente com o cônjuge ante o ciclo evolutivo em que a família se encontra. Rocha, Almeida, Silva e Cezar-Vazet (2011) constataram que o diálogo do casal é uma estratégia de enfrentamento para resolver problemas familiares, ajudando os cônjuges no auxílio de seus problemas profissionais. Em seu estudo, Mendonça e Matos (2015) reconhecem que, nem sempre, é 
possível ter um espaço para conversação, pois, muitas vezes, subsistema conjugal é intersetado pelo parental. Matias, Andrade e Fontaine (2011) evidenciaram que os homens sentem mais o conflito trabalho-família e que as mulheres, por sua vez, sentem mais o conflito família-trabalho. Para os autores, isso reforça as questóes de gênero em que a mulher tem o domínio familiar e que o homem tem o domínio profissional.

Outro ponto presente nesta subcategoria são as políticas públicas e as privadas (dentro das empresas e das instituiçôes). Jablonski e Silva (2011), em seu estudo, concluíram que há uma necessidade de uma revisão nas políticas públicas e privadas voltadas a atender esses novos papéis contemporâneos de homens (pais) e de mulheres (mães), visando a promover uma conciliação entre trabalho e família. Rocha et al. (2011) afirmam, em seu estudo, que o bemestar familiar promove o desempenho pessoal e profissional. Prova disso é que, na pesquisa, Rodrigues, Mazza e Higarashi (2014) constataram que, quando essas profissionais (mães) estão seguras e tranquilas em relação aos cuidados de seus filhos, elas desenvolvem uma vivência melhor de seus papéis. Chama a atenção que os artigos inclusos na amostra analisada não trazem uma reflexão a respeito dos atravessamentos da esfera pública, tais como a lei que obriga as famílias a matricularem suas crianças em escolas a partir dos 4 anos, tampouco sobre condiçôes de trabalho ou ameaças de desemprego, ineficácia do Estado em atender às demandas de educação, saúde e segurança da população, por exemplo (Moreira, Bedran, \& Carellos, 2011).

Ainda, dentro desta subcategoria, há a questão do tempo ante as questões profissionais e pessoais do casal. Closs e Oliveira (2015) comentam as angústias do casal em administrar seu tempo profissional e pessoal com a chegada dos filhos, pois, para muitos, essa nova disponibilidade de tempo para os filhos gera sentimento de culpa e de esforço físico e mental para conciliar esse novo papel (pais) com o profissional. Takahashi, Lourenço, Sander e Souza (2012) concluíram, em sua pesquisa, que, para diminuir o conflito trabalho-família, é necessário, além de compartilhar as atividades familiares, saber administrar o tempo para equilibrar a vida profissional com a vida familiar. Um bom exemplo disso é a pesquisa de Loureiro, Costa e Freitas (2012), a qual mostra que mulheres executivas preferem não assumir responsabilidades maiores em sua vida profissional, pois isso pode estar associado a dedicar mais tempo ao trabalho, mesmo que, para isso, tenham de ganhar menos. 


\subsubsection{MULHER MULTITAREFAS}

Na subcategoria "mulher multitarefas", faz-se uma reflexão da dinâmica familiar com a entrada da mulher no mercado de trabalho. Lopes, DellazzanaZanon e Boeckel (2014), em seu estudo, evidenciaram que a maternidade tardia em mulheres está relacionada à busca de uma independência financeira, ou seja, essas mulheres buscam, primeiramente, uma identidade de trabalhadora para, depois, buscarem a identidade de mãe. Jablonski e Silva (2011) colocam que as mulheres assumem para si o controle doméstico e que, inclusive, têm dificuldades de dividir com seus cônjuges as tarefas domésticas e os cuidados com os filhos. Outro estudo que confirma esse pensamento é o de Guimarães e Petean (2012), em que professores universitários com filhos consideram que as tarefas domésticas e os cuidados com filhos é função feminina, ou seja, as mulheres resistem a um maior engajamento dos companheiros nessas funçóes. Já o estudo de Pasinato e Mosmann (2016) mostra que estão em andamento mudanças em relação a esse fato, pois metade das mães resistem a uma maior participação masculina, já a outra metade promove a inserção dos companheiros nas atividades domésticas e no cuidado com os filhos. Para Guimarães e Petean (2012), a participação maior do homem nas atividades domésticas e no cuidado com os filhos gera maior satisfação na mulher como também melhora o relacionamento conjugal. Outro ponto mostrado na pesquisa de Rodrigues e Izquierdo (2014) é que, quando as mulheres sentem o apoio de seus cônjuges, seu desempenho profissional melhora. Jablonski e Silva (2011) concluíram, em sua pesquisa, que é necessário dessexualizar as competências domésticas, pois só assim vai melhorar a qualidade conjugal e promover um exercício mais democrático da parentalidade, tendo como resultado um aumento das chances de ascensão profissional das mulheres.

Outro ponto levantado nesta subcategoria éa diferenciação de comportamentos das mães e dos pais no mercado de trabalho. No estudo de Takahashi et al. (2012), verificou-se ser a esposa que abdica a carreira profissional em prol do cuidado da família. É ela quem renuncia um trabalho que exige mais do seu tempo, mesmo que isso prejudique seu lado profissional. Isso também ficou evidenciado no estudo de Jablonski e Silva (2011). Para Guimarães e Petean (2012), são as mulheres que faltam ao trabalho em caso de doenças dos filhos ou de outro tipo de acompanhamento necessário. Acrescentando, Rocha et al. (2011) verificaram que, quanto à influência do trabalho na produção, as mulheres apresentam cansaço físico e mental com mais frequência, e que, por causa deste aspecto, são mais suscetíveis à indisposição e à irritabilidade no ambiente familiar. 


\subsubsection{HOMEM PROVEDOR/COADJUVANTE}

A subcategoria "homem provedor/coadjuvante" descreve o comportamento dos pais nas tarefas domésticas e nos cuidados dos filhos. Jablonski e Silva (2011) observaram que os homens são mais distantes das atividades domésticas, alegando falta de tempo e a não delegação de tarefas por parte das esposas, além do cansaço. Fazem o que lhe pedem, mas, geralmente, focam mais no cuidado com os filhos. O estudo de Guimarães e Petean (2012) confirma essa questão, pois, embora os homens estejam ajudando nas tarefas domésticas, seu engajamento é ainda maior no cuidado dos filhos. Para Pasinato e Mosmann (2016), o envolvimento maior dos homens no cuidado dos filhos não reflete uma maior participação deles nas atividades domésticas. Embora os autores reconheçam as dificuldades de transição da parentalidade e dos conflitos em relação aos cuidados dos filhos, para eles, está havendo uma divisão mais igualitária nessas questões.

Outro ponto levantado nesta categoria é a questão do papel de o homem ser provedor. Isso fica evidente no estudo de Takahashi et al. (2012). Em casais em iguais condiçôes educacionais para o mercado de trabalho, é geralmente a mulher quem abdica deste para dedicar-se aos filhos, o que reforça o papel de provedor do homem. Mas essa responsabilidade de provedor para o homem faz com que este não queira assumir riscos profissionais a fim de manter o sustendo da família, como mostrou o estudo de Closs e Oliveira (2015). Pasinato e Mosmann (2016) comentam que a falta de incentivo da parte do Estado também deve ser considerada, pois a legislação brasileira reforça a concepção do homem provedor, instituindo apenas cinco dias de licença paternidade para este e de quatro a seis meses de licença-maternidade para a mulher, impossibilitando um envolvimento conjunto dos genitores quanto a seus filhos. Isso é reforçado por Jablonski e Silva (2011).

Ao identificar a mulher como uma pessoa multitarefas e o homem ainda no papel de provedor, reflexôes do campo dos estudos de gênero teriam contribuído para desvelar esses papéis naturalizados social e culturalmente. Para Jablonski (2010) essa tipificação de gênero, mulher multitarefa e homem provedor, intensifica-se com o surgimento dos filhos, quando o casal adotada uma posição mais tradicional ante os papéis parentais e a rotina de seu lar, mesmo que anteriormente a relação fosse mais igualitária. Isso independe de posição social ou grau de instrução. 


\subsection{REDE DE APOIO}

A segunda categoria deste estudo versa sobre os itens encontrados nos artigos quanto à rede de apoio social, ou seja, com quem o casal poderá contar quando da chegada de um filho. Há de se ter presente ao menos dois pressupostos dessa rede: por um lado, que o apoio social é benéfico; por outro, poderá vir a ser invasivo e estressor. Por isso, faz-se necessária uma negociação com essa rede de apoio quando ela se manifesta intrusiva (Murta, Rodrigues, Rosa, Paulo, \& Furtado, 2011).

Para além do cuidado com a criança que chega ao seio da família, deve-se focar também o apoio ao casal na vivência parental. Assim, a busca de apoio social constitui uma estratégia de enfrentamento para o casal, a fim de diminuir o estresse da chegada do bebê, proporcionando uma melhor qualidade de vida familiar, sendo que a transição parental está entre as principais demandas a serem determinadas (Murta et al., 2011).

Nos estudos sobre esta categoria, emergiram subcategorias. A primeira delas foi o apoio familiar, destacando-se duas figuras: o pai e os avós, principalmente a avó materna; uma segunda subcategoria emersa foi referente aos serviços de saúde que são citados como suporte desde a gestação; a creche emergiu como uma terceira subcategoria, com destaque não somente para o cuidado dos filhos, mas também com a função de ensino, além de favorecer a inserção da mulher no mercado de trabalho; por fim, considerou-se, na quarta subcategoria, outras formas de apoio, destacando-se a empresa, os cuidadores (babás) e os vizinhos.

\subsubsection{APOIO FAMILIAR}

Em se falando de rede de apoio, uma subcategoria que emergiu foi o apoio familiar. Loureiro et al. (2012), nas entrevistas feitas, consideraram a estrutura familiar a base de apoio que supera a ausência da mulher no lar. Já Rodrigues et al. (2014), ao entrevistarem enfermeiras, concluíram que a família se torna a principal rede de apoio no processo de transição parental dessas profissionais.

Nos estudos, emergiu também a figura do pai/marido, em que se limitam a apresentá-lo como rede de apoio à mãe/mulher. Loureiro et al. (2012) constatam na figura paterna o apoio em relação ao cuidado com filhos e com trabalhos domésticos. Murta et al. (2011) também averiguaram o cônjuge como fonte de apoio social na família. Silva, Luz, Cezar-Vaz, \& Silva (2012) apontam que a concepção de paternidade está mais participativa na Contemporaneidade. Esse estudo apontou o homem como aquele que começa a desempenhar novos e diferentes papéis em relação à família. Já no estudo de Jablonski e Silva (2011), 
foi constatado que o homem se sente desobrigado a prestar ajuda quando outro membro da rede de apoio entra em cena.

Um personagem que aparece nos estudos como destaque na rede de apoio familiar é a figura dos avós. Rodrigues et al. (2014) revelam que as mães de seu estudo, ao delegarem os cuidados de uma criança a familiares, em especial à avó materna, todos o fazem por se sentirem mais seguros e, quanto aos avós paternos, estes têm uma menor participação nos cuidados. Mainetti e Wanderbroocke (2013), em sua pesquisa, chegam à conclusão de que o trabalho dos avós assume um novo significado com a chegada dos netos e é preciso perceber as diferenças de papéis de pais e de avós: pais têm a função de educar, e os avós têm a missão de transmitir conhecimentos e valores. Além do mais, fazem um alerta quanto à disponibilidade dos avós em cuidar dos netos, o que poderá acarretar um aumento da probabilidade de os pais não assumirem ou assumirem parcialmente as funções parentais. Pinto, Pontes e Silva (2013) colaboram com a ideia e constatam que os avós assumem o papel parcial ou integral no cuidado das crianças e optam por uma rede multigeracional, a qual a avó está inserida. Naffah Neto(2011) percebeu, em seu estudo, o papel da avó como substituta da mãe, sendo mais permissiva e menos exigente, e o avô que assume um papel mais periférico.

\subsubsection{SERVIÇOS DE SAÚDE}

Outra subcategoria que emergiu dos artigos refere-se aos serviços de saúde. Estes, na constatação de Murta et al. (2011), devem estar prontos a oferecer informações apropriadas, de modo adequado, a casais na transição parental e, para tanto, sugerem que sejam elaborados programas de transição nas açôes bem como na gestação, a fim de reduzir a ansiedade do casal. Silva et al. (2012) consideram importante o subsídio do serviço de saúde com famílias de filhos pequenos em que ambos os pais trabalham em suas profissões, a fim de se ter um conhecimento desejado do trabalho familiar entre o casal.

\subsubsection{CRECHE}

Outra subcategoria encontrada nos artigos analisados foi a creche. $\mathrm{Na}$ dificuldade de o casal conciliar vida profissional e doméstica, a creche surge como dispositivo para suprir essa dificuldade no cuidado com os filhos (Silva et al., 2012). Esta é dada por Queiroz e Aragón (2015) como importante no processo de inserção e de participação da mulher no mercado de trabalho. Para Pasinato e Mosmann (2016), a creche auxilia os pais no desempenho da 
coparentalidade. Na pesquisa de Rodrigues et al. (2014), acrescenta-se à creche, além dos cuidados com a criança, a função de ensino que favorece a criança em formação bem como sua família.

\subsubsection{OUTRAS FORMAS DE APOIO}

Nesta subcategoria, inicia-se descrevendo o papel da empresa ou da instituição dentro da rede de apoio, colocando esta num papel ativo dentro da dinâmica do nascimento do filho de seus colaboradores. Murta et al. (2011), em seu estudo, verificaram que uma das necessidades dos participantes referente aos programas voltados para auxílio na chegada de filhos é que estes deveriam começar bem antes, de preferência ainda na gestação. Guimarães e Petean (2012) concluem que as empresas e o governo devem buscar estruturas de apoio fora da esfera familiar, como forma de diminuir o estresse e a tensão de seus colaboradores de dupla renda. Já a pesquisa de Oliveira, Cavazotte e Paciello (2013) mostra que os programas voltados para os filhos são pouco abrangentes e se limitam à ordem financeira, pois, para os pesquisados, esses programas deveriam ir mais além, considerando, em especial, a questão do tempo. Outro exemplo vem da pesquisa de Teixeira e Nascimento (2011), em que a implantação de programas de férias para filhos dos colaboradores minimiza o conflito dos pais em onde deixar os filhos com segurança nas férias destes.

A figura da babá emergiu como rede de apoio em dois estudos. Loureiro et al. (2012) constatam que as mulheres que ocupam cargos mais elevados na empresa contam com o apoio de empregadas domésticas e de babás, as quais assumem funções que, antes, apenas a mãe desenvolvia e que orientações quanto a valores e a limites não costumam ser delegadas. Uma das participantes da pesquisa de Closs e Oliveira (2015, p. 539) afirmou: "Eu tinha estrutura, tinha babá, tudo", ou seja, a babá como forma de mantenedora de uma estrutura.

Também, em dois estudos, são apontados os vizinhos como rede de apoio. Mainetti e Wanderbroock (2013) consideram-nos cuidadores colaborativos que auxiliam na adaptação parental. Já Pinto et al. (2013) os consideram como uma rede social mais ampla de ajuda mútua, em que há troca de favores e de solidariedade.

No contexto atual, o salário pago ao cargo de babá é inviável para muitas famílias, o que pode sobrecarregar os avós com o cuidado dos netos. No entanto, ainda que não tenha sido apontado até então no estudo, parece que o poder econômico amplia as possibilidades de apoio para as famílias mais favorecidas, o 
que pode facilitar o cotidiano familiar, especialmente na conciliação dos papéis parentais e profissionais, diante da chegada do bebê.

O fato de a família aparecer como o principal apoio também pode estar relacionado à fragilidade das outras forma de apoio que apareceram no estudo. Serviços de saúde que funcionam somente em horário comercial, período que os pais estão trabalhando. Além disso, a disponibilidade de vagas em creche públicas frequentemente não atende à demanda na realidade brasileira.

\section{CONSIDERAÇŌES FINAIS}

O objetivo deste estudo foi revisar sistematicamente evidências sobre a rede de apoio que uma família em formação pode contar quando do nascimento de um filho e como conciliar família-trabalho/trabalho-família na atualidade.

O que ficou evidenciada neste estudo é a estreita relação existente entre o CFT e CTF. Possivelmente, há uma relação mútua de causa e de efeito, ou seja, o desajuste em uma gera interferência na outra, e vice-versa. Há de se pensar nas diferenças quanto à profissão exercida. Algumas exigem um tempo extra, além daquele dispensado na empresa. Assim, atividades laborais são trazidas para serem realizadas em casa, afetando o tempo destinado à convivência conjugal, ao desenvolvimento de atividades domésticas e ao cuidado com filhos. Também há de se pensar que questôes familiares poderão tirar o trabalhador de suas funções na empresa, o que poderá acarretar conflitos. Assim, o que fica retratado é que trabalho e família são dois construtos que acompanham a vida de adultos economicamente ativos.

A rede de apoio emergiu dos estudos como forma de dar suporte principalmente à mãe da criança, sendo que o pai foi considerado como rede de apoio, coadjuvante no processo parental. Ainda que coadjuvante, a literatura já aponta avanços na implicação do pai nos cuidados da criança. Há uma transformação que ocorre lentamente, pois envolve modificações de papéis parentais estáticos e rígidos, consolidados em nossa cultura. Cabe ressaltar a importância, cada vez maior, de "empoderar" esse pai, a fim de que possa assumir mais conjuntamente com a mãe o cuidado com os filhos e as tarefas domésticas, com o intuito de minimizar conflitos familiares e melhorar a relação conjugal. É preciso que a mulher, na definição de seu papel de mãe, permita ao homem exercer seu papel de pai e não se sinta responsabilizada por algo que se constituiu socialmente na história, ou seja, que ela se coloque no lugar de grande responsável pelo cuidado dos filhos e pelas atividades domésticas. Isso precisa ser partilhado com seu companheiro. Essa perspectiva passa pela educação das novas gerações. 
Assim, quando as angústias são partilhadas entre o casal numa atitude de constante diálogo, facilita a escolha da rede de apoio mais apropriada. Lembrando que cada família tem um tipo de funcionamento, e o que pode ser adaptativo para ela quanto à rede de apoio poderá não o ser para outra família. No que se referiu ao casal, quando ambos estão trabalhando, os avós são considerados o apoio mais confiável, sendo as avós maternas as mais atuantes. Presume-se que isso se deva ao vínculo maior com a mãe da criança.

Por fim, julga-se importante que se façam estudos futuros em que sejam envolvidas diferentes configurações familiares e que se utilizem de métodos de triangulação de dados para pesquisar a rede de apoio a casais que trabalham e que têm filhos pequenos. Além disso, outras características de famílias que não foram foco deste estudo podem ser interessantes, tais como famílias cujos filhos necessitem de institucionalização ou tenham necessidades especiais, ou em que os cuidadores não estão trabalhando. Também é importante incentivar as pesquisas empíricas brasileiras que envolvam a saúde e o bem-estar do trabalhador e estejam relacionadas ao desenvolvimento infantil, para que se propaguem, de forma fundamentada, boas práticas no trabalho e na valorização da convivência familiar em empresas públicas e privadas. 


\section{REFERENNCIAS}

Closs, L. Q., \& Oliveira, S. R. (2015). História de vida e trajetórias profissionais: estudo com executivos brasileiros. Revista de Administração Contemporânea, $19(4), 525-543$.

Decreto $\mathrm{n}^{\mathrm{o}}$ 7.052, de 23 de dezembro de 2009. (2009, 23 dezembro). Regulamenta a Lei no 11.770 , de 9 de setembro de 2008, que cria o Programa Empresa Cidadã, destinado à prorrogação da licença-maternidade, no tocante a empregadas de pessoas jurídicas. Diário Oficial da União, Brasília. Recuperado a partir de http://www.planalto.gov.br/ccivil_03/_ato2007-2010/2009/ decreto/d7052.htm

Dessen, M. A., \& Braz, M. P. (2000). Rede social de apoio durante transições familiares decorrentes do nascimento de filhos. Psicologia: Teoria e Pesquisa, 16(3), 221-231.

Guimarães, M. G. V., \& Petean, E. B. L. (2012). Carreira e família: divisão de tarefas domiciliares na vida de professoras universitárias. Revista Brasileira de Orientação Profissional, 13(1), 103-110.

Jablonski, B. (2010). A divisão de tarefas domésticas entre homens e mulheres no cotidiano do casamento. Revista Psicologia: Ciência e Profissão, 30(2), 262275.

Jablonski, B., \& Silva, M. S. (2011). D(e)scolar de casa: dilemas contemporâneos dos casais de aeronautas. Psicologia em Revista, 17(2), 196-210.

Lei no 11.770, de 9 de setembro de 2008. (2008, 9 setembro). Cria o Programa Empresa Cidadã, destinado à prorrogação da licença-maternidade mediante concessão de incentivo fiscal, e altera a Lei no 8.212, de 24 de julho de 1991. Diário Oficial da União, Brasília. Recuperado a partir de http://www.planalto. gov.br/ccivil_03/_ato2007-2010/2008/lei/l11770.htm

Lopes, M. N., Dellazzana-Zanon, L. L., Boeckel, M. G. (2014). A multiplicidade de papéis da mulher contemporânea e a maternidade tardia. Revista Temas em Psicologia, 22(4), 917-928.

Loureiro, C. M. P., Costa, I. S. A., \& Freitas, J. A. S. B. (2012). Trajetórias profissionais de mulheres executivas: qual o preço do sucesso? Revista de Ciências da Administração, 14(33), 130-144. 
Mainetti, A. C., \& Wanderbroocke, A. C. N. S. (2013). Avós que assumem a criação de netos. Revista Pensando Famílias, 17(1), 87-98.

Matias, M., Andrade, C., Fontaine, A. M. (2011). Diferenças de gênero no conflito trabalho-família: um estudo com famílias portuguesas de duploemprego com filhos em idade pré-escolar. Ediçōes Colibri, 25(1), 9-32.

Mendonça, M., \& Matos, P. M. (2015). Conciliação família-trabalho vivida a dois: um estudo qualitativo com casais com filhos pequenos. Análise Psicológica, 33(3), 317-334.

Mizrahi, B. G. (2004). A relação pais e filhos hoje: a parentalidade e as transformaçôes no mundo do trabalho. São Paulo: Loyola.

Moreira, M. I. C., Bedran, P. M., \& Carellos, S. M. S. D. (2011). A família contemporânea brasileira em contexto de fragilidade social e os novos direitos das crianças: desafios éticos. Psicologia em Revista, 17(1), 161-180.

Murta, S. G., Rodrigues, A. C., Rosa, I. O., Paulo, S. G., \& Furtado, K. (2011). Avaliação de necessidades para a implementação de um programa de transição para a parentalidade. Psicologia: Teoria e Pesquisa, 27(3), 337-346.

Naffah Neto, A. (2011). O lugar e a função do avô, aquele que é pai duas vezes: um estudo a partir de D. W. Winnicott. Winnicott e-prints, 6(2), 1-15.

Oliveira, L. B., Cavazotte, F. S. C., \& Paciello, R. R. (2013). Antecedentes e consequências dos conflitos entre trabalho e família. Revista de Administração Contemporânea, 17(4), 418-437.

Pasinato, L., \& Mosmann, C. P. (2016). Transição para a parentalidade e a coparentalidade: casais que os filhos ingressaram na escola ao término da licença-maternidade. Avances en Psicología Latinoamericana, 34(1), 129-142.

Pinto, N. M. A., Pontes, F. A. R., \& Silva, S. S. C. (2013). A rede de apoio social e o papel da mulher na geração de ocupação e renda no meio rural. Temas em Psicologia, 21(2),297-315.

Queiroz, V. S., \& Aragón, J. A. O. (2015). Alocação de tempo em trabalho pelas mulheres brasileiras. Estudos Econômicos, 45(4), 787-819.

Rocha, L. P., Almeida, M. C. V., Silva, M. R. S., \& Cezar-Vaz, M. R. (2011). Influência recíproca entre atividade profissional e vida familiar: percepção de pais/mães. Acta Paulista de Enfermagem, 24(3), 373-380. 
Rodrigues, B. C., Mazza, V. A., \& Higarashi, I. H. (2014). Rede social de apoio de enfermeiras-mães no cuidado com os filhos. Texto \& Contexto Enfermagem, 23(2), 460-468.

Rodrigues, H. S. J., \& Izquierdo, J. (2014). Da vida doméstica ao trabalho formal: uma análise do processo de inserção de donas de casa no mercado de trabalho Ártemis, 18(1); 228-238.

Silva, M. R. S., Luz, G. S., Cezar-Vaz, M. R., \& Silva; P. A. (2012). Trabalho familiar: distribuição desejada do trabalho doméstico e cuidados dos filhos entre cônjuges. Revista Gaúcha de Enfermagem, 33(1), 124-131.

Takahashi, A. R. W., Lourenço, M. L., Sander, J. A., \& Souza, C. P. S. (2012). "E agora, José?": intraempreendedorismo, desenvolvimento de competências empreendedoras e conflito trabalho-família com professores de programas de mestrado e doutorado em administração. In Encontros Cientificos Tourism \& Management Studies, 4, 1208-1219.

Teixeira, R., \& Nascimento, I. (2011). Conciliação trabalho-família: contribuiçôes de medidas adotadas por organizações portuguesas. Revista Brasileira de Orientação Profissional, 12(2), 215-225.

Vasconcelos, V. M. R., Seabra, K. C., Eisenberg, Z. W., \& Moreira, A. R. C. P. (2012). O lugar da creche nos debates sobre parentalidade e coparentalidade. In Piccinini, C. A., \& Alvarenga, P. (Orgs.). Maternidade e paternidade: a parentalidade em diversos contextos. (pp. 341-366). São Paulo: Casa do Psicólogo. 